\title{
$\underline{\mathbf{P}-181}$
}

\section{Antioxidant and Antihyperlipidemic Effects of the Aqueous Extract from Ficus Deltoidea var. Kunstleri Fruit and its Water Fraction IN Streptozocin-Induced Diabetic Rats}

\author{
Hasni Misbah ${ }^{1, *}$, Azlina Abdul Aziz ${ }^{1,3}$ and Norhaniza Aminudin ${ }^{2,3}$ \\ ${ }^{I}$ Department of Molecular Medicine, Faculty of Medicine, University of Malaya, 50603 Kuala Lumpur, Malaysia; \\ ${ }^{2}$ Institute of Biological Sciences, Faculty of Science, University of Malaya, 50603 Kuala Lumpur, Malaysia; ${ }^{3}$ University \\ Malaya Centre for Proteomics Research (UMCPR), Medical Biotechnology Laboratory, Faculty of Medicine, University \\ of Malaya, 50603 Kuala Lumpur, Malaysia; E-mail: hasni@um.edu.my
}

Diabetes mellitus is a chronic metabolic disorder and has been associated with not only high blood sugar levels, but also lipid abnormalities and oxidative stress. In the present study, the antioxidant and antihyperlipidemic potentials of the fruit from Ficus deltoidea var. kunstleri were evaluated in vivo in normal and streptozocin-induced diabetic rats. The crude aqueous extract and its water fraction were administered orally to normal and diabetic rats for 21 consecutive days. Apart from that, glibenclamide was used as a reference drug at a dose of $5 \mathrm{mg} / \mathrm{kg}$ body weight. At the end of the treatment, serum and liver homogenate were analyzed for antioxidant capacities using ABTS, FRAP and TBARS assays. The level of lipid peroxidation, antioxidant enzymes as well as serum lipid profile were also evaluated. Diabetic rats showed a marked decrease in the ABTS free radical scavenging activities, ferric reducing properties and activities of antioxidant enzymes. Hyperglycaemia was also shown to be associated with raised serum triglycerides and LDL levels, and a reduced level of HDL. Administration of F. deltoidea significantly reversed these changes back to near normal level with the crude aqueous extract exhibiting greater effect. The results confirmed that the fruit of $F$. deltoidea var. kunstleri is beneficial in reducing oxidative stress and improving lipid profile, thus minimizing the complications of diabetes mellitus. Additionally, proteomics analysis of the serum proteome demonstrated some changes in the lipid-related proteins which further support the hypolipidemic effect of $F$. deltoidea.

Keywords: Ficus deltoidea, antioxidant, diabetes; lipid, proteomics. 